\title{
Model Tabanlı Tasarım ile Eş-Zamanlı Mühendislik: Mikro-Türbin Uygulama Örneği
}

\author{
Olcay Sarı ${ }^{* 1}$, Orçun Bulat ${ }^{2}$, Onur Tunçer ${ }^{3}$, Çağlar Üçler ${ }^{4}$
}

\section{ÖZ}

Mühendislik sistemlerinin tasarımı ve geliştirilmesi karmaşık bir süreçtir ve birbirine bağlı çok sayıdaki sistem parametresinin en iyi değerlere ulaşması gerekmektedir. Özellikle gaz türbinleri gibi birçok farklı alt sistemlerden oluşan sistemlerin en verimli tasarım noktasını elde etmek farklı disiplinlerden uzmanların ortak çalışmasını gerektirir. Netice olarak, model tabanlı yazılım ortamlarında matematiksel modellerinin geliştirilmesi ve eş-zamanlı mühendislik süreci uygulanabilir. Bu süreç boyunca V-döngülü sistem mühendisliği sayesinde kavramsal tasarımın oluşturulup tartışılması, alt istemlerin detay tasarımların gerçekleştirilip entegrasyonu sonrası test simülasyonları ile optimum tasarım noktasının elde edilmesi mümkündür. $\mathrm{Bu}$ tasarım süreçleri, birbirleri ile etkileşimleri ve örnek bir mikro-türbin sisteminin geliştirilme süreci bu yayın içerisinde uygulama örneği olarak ele alınmaktadır.

Anahtar Kelimeler: Model-tabanlı tasarım, eş-zamanlı mühendislik, V-döngüsü sistem mühendisliği

\section{Concurrent Engineering With Model Based Design: A Micro- Turbine Application}

\begin{abstract}
Design and development of engineering systems is a complex process, requiring the optimization of interconnected system parameters. Especially, the determination of the design point of systems like gas turbines with distinct subsystems requires the collaboration of cross disciplinary experts. Consequently, mathematical models in model-based-software environment and concurrent engineering process can be used, where the V-cycle within system engineering enables the development of conceptual design, detailed design of subsystems, integration and the consequent optimization of the design with simulations aggregating in an optimum design point. This design processes and associated trade-offs are explained here though a micro-turbine case study
\end{abstract}

Keywords: Model-based design, concurrent engineering, V-cycle system engineering

\footnotetext{
İletişim Yazarı

Geliş/Received

Kabul/Accepted

06.01 .2019

: 27.11.2019

1 İstanbul Teknik Üniversitesi, Fen Bilimleri Enstitüsü, İstanbul - sariol@itu.edu.tr ORCID: 0000-0002-3368-5603

2 Roma Sapienza Üniversitesi, Makine ve Havacılık Mühendisliği Fakültesi, Roma - orcunbulat@gmail.com ORCID: 0000-0001-8046-4363

3 Prof. Dr., İstanbul Teknik Üniversitesi, Uçak ve Uzay Bilimleri Fakültesi, İstanbul - tuncero@itu.edu.tr ORCID: 0000-0002-2803-1146

4 Doç. Dr., Özyeğin Üniversitesi, Havacılık ve Uzay Bilimleri Fakültesi, İstanbul - caglar.ucler@ozyegin.edu.tr ORCID: 0000-0003-4209-7915
} 


\section{GÍRİŞ}

Mühendislik sistemlerinin tasarımı ve geliştirilmesi çok farklı disiplinlerden uzmanların ortak çalışmasını gerektirir. Eş-zamanlı ortamı kapsayan sistemin belirsiz ön tasarım aşamalarında gerek disiplinler arası, gerekse de geliştirilen sistemin alt yapıtaşları arasında bilgi ve ihtiyaç iletişsimi gereklidir. Ancak bu sayede oluşturulan konfigürasyon ve ön tasarım evrilerek başarılı bir ürüne dönüşebilir. Disiplinler arası mühendislik çalışmaları için sistem temelinde model tabanlı tasarım yaklaşımı, taslak oluşturmayı ve farklı ekiplerin ortak çalışmasını kolaylaştıran bir modeldir. Böylece ihtiyaçlar üst seviyede belirlendikten sonra, model tabanlı tasarım ile disiplinler arası (akış, 1sı, mekanik, elektrik-elektronik) ekipler, sistemin farklı parçaları üzerinde aynı anda beraber veya birbirlerinden bağımsız olarak V-döngüsü içinde çalışabilmektedir.

Sonuç olarak, sistemin her bir bölümü kendi iç kodlarıyla bağımsız olarak modellenir. Bağımsız olarak geliştirilen bu alt modellerin tümü, bileşenlerin tutarlılığını kontrol etmek için birbirlerine bağlanır ve çeşitli çalışma koşulları için sistemin yeterliliğini inceler. Başarılı bir entegrasyonun sağlanabilmesi için standart ve başlangıç parametreleri V-döngüsü boyunca ayarlanır. Bu şekilde, oluşturulan sanal model ile ya da sanal modelin kısmi prototiplere bağlanması ile gerçek zamanlı simülasyonlar yürütebilir, eniyileme çalışmaları yapılabilir.

$\mathrm{Bu}$ çalışmada tabanlı tasarım ile eş-zamanlı tasarım anlatılarak, V-döngüsü sistem mühendisliği yaklaşımının uygulaması açıklanmaktadır. Akabinde bu yaklaşımlara bir örnek oluşturması için mikro-türbin sistemi geliştirme süreci ve bu tasarım metotlarının bu süreçteki etkileri de ayrıca paylaşılmaktadır.

\section{MODEL TABANLI TASARIM}

Model tabanlı tasarımın amacı, tasarımcıların etkileşimli yazılım uygulamalarını uygulama düzeyini derhal başlatmak yerine daha semantik odaklı bir seviyeden belirlemesine ve analiz etmesine olanak tanıyan üst düzey modelleri tanımlamaktır [1]. Ayrıca, karmaşık kontrol, sinyal işleme ve iletişim sistemlerinin tasarımı ile ilgili problemlerin odaklanması için matematiksel ve görsel bir yöntem olarak tanımlanmaktadır [2-4]. Bu yöntemle, tasarımcılar sürecin daha önemli yönlerine konsantre olurlar. Dolayısıyla, geliştirme ve iyilieştirme süreçleri boyunca sık yapılan analizler sayesinde süreç daha sorunsuz bir şekilde yönetilebilmektedir. Buna ek olarak, tasarımcılar kısıtları karşılamak ve en iyi dengeyi bulmak için bu yöntemi kullanabilir [5].

Model tabanlı tasarım, diğer geleneksel yaklaşımlara kıyasla önemli avantajlar sunmaktadır [1,3]. En önemlisi genel iletişim, veri analizi ve geliştirme ekipleri arasındaki sistem doğrulamalarını kolaylaştıran ortak tasarım ortamıdır [6-8]. Dahası, mühendislerin, sistem değişikliğinin zaman ve maddi etkisi azaltıldığında sistem tasarımının erken evrelerindeki hataları bulmaları ve düzeltmeleri mümkündür [6-8]. Bunun yanı sıra, bu teknik terfi (iyileştirme) ve türev sistemlerin kapasitelerini genişletmek için 
tasarımın yeniden kullanılmasını kolaylaştırır [8]. Bu teknikle, sistemler ve ürünler piyasaya daha hızlı ulaşır ve geleneksel yöntemlere kıyasla daha düşük maliyetli olur [11]. Özellikle havacılık ve otomotiv uygulamaları arasında bu yöntemin kullanımı yaygındır, aynı zamanda gömülü yazılım tasarımı için de sıklıkla uygulanan bir metodolojidir $[6,9,10]$.

Model tabanlı tasarım, geliştirme sürecini (V-diyagramı) desteklerken, tasarım süreci boyunca değişik disiplerden takımlar arasında iletişim için ortak bir yapı oluşturur [7]. Ürünün kontrol sistemlerinin de entegrasyonu model tabanlı tasarım ile yapılabilir. $\mathrm{Bu}$, ürünün modellenmesi sonra kontrolcü analizi ve sentezini, çevrimdışı simülasyonu ve gerçek zamanlı simülasyonu, nihayetinde de gömülü kodun oluşturulup dağıtımını da içeren tümleşik bir yaklaşımdır [7,11,12].

Geleneksel tasarım yöntemleri ile model tabanlı tasarım paradigması arasındaki bir diğer fark ise karmaşık yapılar ve kapsamlı yazılım kodu yerine, model tabanlı tasarım yaklaşımının sürekli ve ayrık zamanlı yapı blokları kullanarak gelişmiş ve işlevsel özelliklere sahip modelleri tanımlayarak kullanıyor olmasıdır. Simülasyon yazılımları ile oluşturulmuş modeller, hızlı prototiplendirme, yazılım testleri ve sonuçları doğrulamaya yardımcı olabilir. Test ve doğrulama süreci gelişmiş olmakla kalmaz, aynı zamanda bazı durumlarda, yeni tasarım paradigması ile sistemdeki dinamik etkilerin geleneksel tasarım yöntemine kıyasla daha hızlı ve verimli bir şekilde elde edilmesini sağlanır.

\section{EŞ-ZAMANLI TASARIM}

Entegre ürün geliştirme veya yinelemeli yöntem olarak da adlandırılan "eş-zamanlı mühendislik", tasarım ve ürün geliştirme aşamalarının sürekli revize edilmesini sağlayan görevleri paralel hale getirmek için kullanılan sistematik bir yaklaşım olarak tanımlanabilir. Bu yöntemde müşterilerin beklentilerini karşılamak ve piyasaya yeni bir ürün sürmek için geçen süreyi azaltmak amaçlanmaktadır. Bu yaratıcı ve modern sistemin arkasındaki fikir, süreç boyunca yaşanan sorunların üzerinde fazla zaman ve ek mali kaynaklar harcamaksızın kolayca ayarlanabileceği veya yeniden düzenlenebileceği en hızlı ve en ucuz ürüne ulaşmaktır. Basit olarak ürün geliştirme aşamalarının eş-zamanlı yürütülmesini gerektirir [13,14].

Eş-zamanlı mühendislik ayrıca ürün etkenliği, imalat, montaj, test, bakım, güvenilirlik, maliyet ve kalite gibi unsurların bulunduğu tasarım aşamasında ürünün ömrü ile ilgili faktörlerin dikkate alınması olarak da açıklanmaktadır. Bu faktörler sadece bu yaklaşımı önemli kılmakla kalmaz, aynı zamanda ürün kalitesi ve maliyetinin hedeflerini genellikle başlangıçtan belirlenmesini sağlar. Eş-zamanlı etkinliklerin yanı sıra ekipler arasındaki işbirliği ürüne rekabet gücü sağlar ve karlılığındaki verimi arttırır. Bu nedenle, eş-zamanlı mühendislik, organizasyonlara genel bir çerçeve sağlamayı ve genelde piyasa süresine, ürün maliyetine, pazar payına ve kaliteye dayalı verimliliği artırmayı amaçlamaktadır [15]. 
Eş-zamanlı mühendislik son dönemde hızla olgunlaşıp, mühendislik tasarım döngülerini optimize etmek için bilinen en etkili yaklaşımlarından biri haline gelmiştir [16]. Günümüzde eş-zamanlı mühendislik, ürün geliştirmede çok yoğun kullanılmaktadır. Eş-zamanlı mühendisliğin uğraştığı önemli sorunlarından biri, ürün geliştirme sürecinin erken aşamalarında nasıl karar verilebileceğidir [17]. Bu gibi kararlar için görevler ve fonksiyonlar arasındaki bağımlılıkları modelleyen programlar ile desteklenen tasarım ve gereksinim yönetimi gerekir $[18,19]$. Bu erken aşama tasarım değerlendirmeleri esnasında, mühendisler ve ekipler arasındaki iletişim eksikliği problemlere sebep olabilir [20]. Eş-zamanlı bir tasarım süreci, pratikte zor olabilecek modellerin (bilgisayar destekli tasarım, sonlu elemanlar yöntemi, gömülü yazılım, simülasyon gibi) verimli bir şekilde etkileşimli kullanılmasını beklemektedir. Aksi halde, bu konular doğru bir şekilde ele alınmazsa, sistem işe yaramayabilir [21]. Bu noktada model tabanlı tasarımın eş-zamanlı mühendisliği destekler nitelikte olduğu görülmektedir.

Eş-zamanlı mühendislik, iki kavram etrafında vücut bulur:

i. Ürün ömrü döngüsünün tüm unsurlarının fonksiyonellik, üretilebilirlik, montaj ve test edilebilirlik için değerlendirilmesi [20],

ii. Eş-zamanlı olarak tüm bu tasarım faaliyetlerinin gerçekleştirilmesi. Böylece gerektiğinde ihtiyaçlar yeniden düzenlenerek, ürün kalitesini arttırılması, hızlı ama maliyet etkin tasarım hedeflenir [14].

Geleneksel doğrusal tasarımın aksine eş-zamanlı mühendislik, tasarımın tüm yönlerinin aynı anda hesaba katılmasıyla daha evrimsel bir yaklaşıma izin veren bir döngüde çalışır (bkz. Şekil 1) ve dört farklı unsurdan müteşekkildir [23]:

- Yazılım ve donanım tasarımı, imalat pazarlaması, finans gibi çeşitli disiplinlerden oluşan işlevsel ekipler,

- Değişik faaliyetlerin aynı anda yürütülmesi,

- Disiplinler arası işlevsel takımlar ile bilgi paylaşılması,

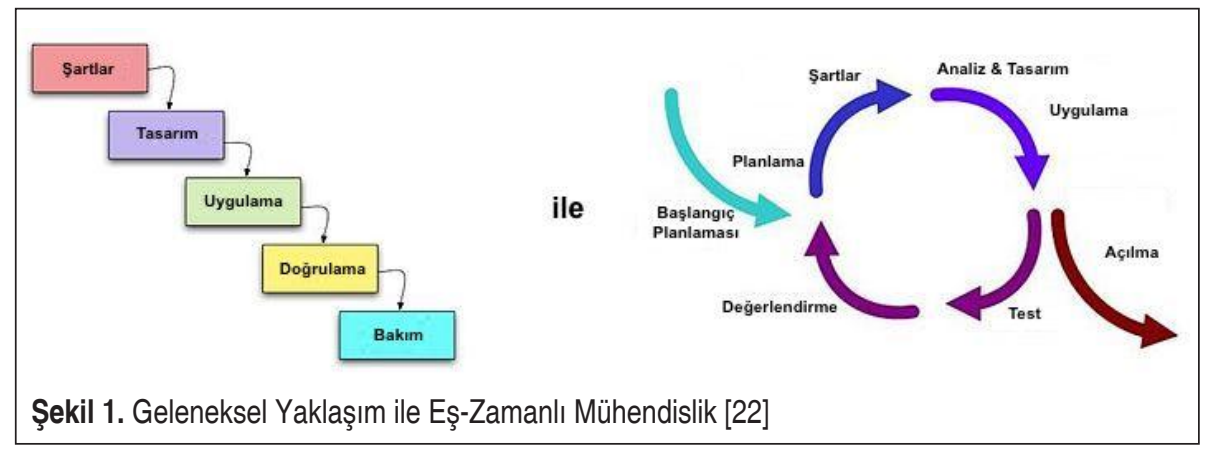


- Entegre proje yönetimi.

Eş-zamanlı mühendisliğin uygulanması için, takım temelli veya bilgisayar tabanlı yaklaşımlar kullanılabilir [24]. Ekip esaslı uygulamada ekip ve üyeleri, kapasitelerine ve ürüne potansiyel katkılarına göre seçilir. Donanım ve yazılım araçlarındaki ilerlemeler, üyelerin tasarımdaki çeşitli niteliklerin, özellikle de son aşamadaki etkilerini göz önüne almasını sağlar. Bu ekip yaklaşımı sürecin başından sonuna kadar karışık sorunları çözme için uygun bir yoldur. Bilgisayar tabanlı uygulamada ise ek olarak kullanılan yazılımlar ile iletişim desteklenir ve yaşam döngüsünün tüm etkileri göz önüne alınır [25]. Kullanılan araçlar ile model oluşturma, simülasyon, hızlı prototipleme ve kontrol sistemleri geliştirmesi desteklenir.

Özellikle üretim, enerji ve havacılık endüstrilerinden, eş-zamanlı mühendislik sistemi başarıyla uygulanan birçok şirket ve kuruluş bilinmekle birlikte muhtemelen bu konuda lider alternatif tasarım setli eş zamanlı mühendislik (Set-Based Concurrent Engineering - SBCE) yaklaşımları ile Toyota'dır [26]. Toyota'nın eş-zamanlı mühendislik ve takım tabanlı eş-zamanlı mühendisliği hayata geçirme süreci, büyük otomobil üreticilerinin kazançlarını aşarak son derece etkili olmuştur ve günümüze kadar da çok ilerlemiştir [26,27]. Ayrıca havacılıkta Avrupa Uzay Ajansı (ESA)'nın Eş-zamanlı Tasarım Tesisi gibi kuruluşlarda SwissCube nano-satellite ve hibrit motosiklet gibi birçok başarılı proje başlatılmıştır [28,29]. Bu projelerin hepsinin ortak noktası olarak eş-zamanlı mühendisliği bilgisayar destekli ortamlarda etkinleştiren V-Döngüsü ve Sistem Mühendisliği aşağıda anlatılmıştır.

\section{V-DÖNGÜSÜ SISTEM MÜHENDİSLİ̆̈I}

V-döngüsü doğrulama modeli olarak da adlandırılan V-döngüsü sistem mühendisliği, sistemlerle ilgili karmaşıklığı basitleştirmek üzere tasarlanmış kavramsal modelden oluşan tasarım yöntemidir [30-31]. Burada yaşam döngüsü modelleri ve proje

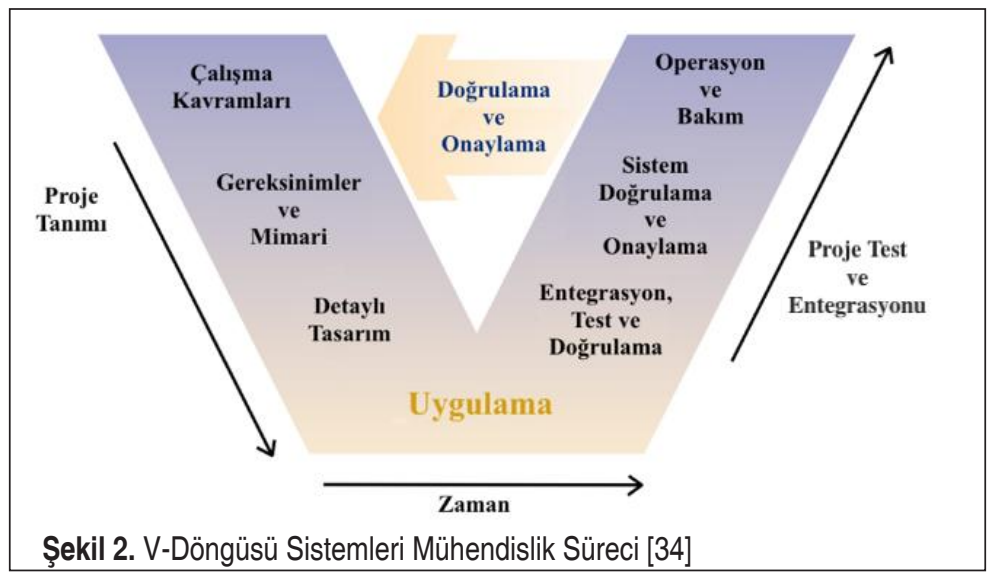


yönetimi modelleri üzerine odaklanılır. V döngüsü konsept ve kavram geliştirme ile başlayarak, tasarım, uygulama ve entegrasyon sonrası test ve operasyon ile ürünün tüm yaşam çevrimini temsil eder [32]. Eş-zamanlı mühendislik ile doğrusal tasarımı yerine, süreç V içerisinde her seviyede evrilerek ilerler. Böylece sol kısım kavram geliştirme, gereksinimlerin ve şartnamelerin oluşturulması sonrası tasarımı temsil ederken, sağda ise ilgili seviyelerde parçaların ve sonrasında sistemin entegrasyonuyla sol kol ile doğrulanmaları ve operasyonla bakım temsil edilmektedir; dolayısı ile zamana yayılan işlemler Şekil 2'de gösterilen V üzerinde ilerleyerek gerçekleştirilmektedir $[31,33]$.

Sonuç olarak V-modeli, şirketlerin ve tasarımcıların projelerin planlanması ve gerçekleştirilmesi konusunda rehberlik etmelerine yardımcı olur. V-modeli kullanımı ile proje riskleri en aza indirgenerek, kalitenin iyileştirilmesi sağlanır ve güvence altına alınır; böylece sistem ömrü boyunca toplam maliyetin azaltılması ile tüm paydaşlar arasındaki iletişimin iyileştirilmesi hedeflenir [30]. V-döngüsü modeli, basit ve kolay kullanımı ile gerekliliklerin ve hedeflerin açıkça tanımlandığı projeler için çok iyi çalışır [35].

Günümüzde, V-döngüsü oldukça yaygın bir standart halini almıştır. İlk olarak AIBG firması tarafından zamanında Alman Federal Savunma Bakanlığı için geliştirilmiş olan model, günümüzde birçok ihale sürecinde de temel oluşturmaktadır [30]. V-döngüsü daha sonra Amerika' da da donanım, yazılım ve insan etkileşimi olan sistemlerde kullanılmaya başlanmıştır [31]. Hughes (şimdiki Raytheon Şirketi'nin bir parçası), 1982 yılında ilk V-modelini havacılık için FAA İleri Otomasyon Sistemi (AAS) programında kullanmıştır [36]. Günümüzde ise sistem mühendisliği süreci etkileşimleri için V-döngüsü yoğun olarak proje yaşam döngüsü ile birlikte mühendislik tasarımlarında kullanılmaktadır [32, 37, 38]. Bu sürecin örneklenebilmesi adına mikro-türbin özelinde yapılan bir çalışma aktarılmaktadır.

\section{MIKRO-TÜRBIN UYGULAMA ÖRNEĞİ}

Jenerik bir mikro-türbinin birçok karmaşık sistemi, doğrusal olmayan davranışları ile bağımsız olarak tasarlanıp sonradan bu sistemler birbirleri ile dijital ortamda entegre edilerek belirli bir performans düzeyinde uyum içerisinde çalıştırarak mikro-türbin sistemi tasarlanmıştır. Bu çalışmadaki alt sistemler kompresör ve türbini ikilisi, yanma odası, reküperasyon ve atık 1sı geri kazanımı işin gerekli eşanjörler, yağ ve su tankları, pompalar ve elektrik üretimi için gerekli alternatör olarak sıralanabilir.

$\mathrm{Bu}$ çalışmada çoğunlukla doğrusal olmayan sistemlerin tasarımında disiplinler arası simülasyon ortamı olan MATLAB/Simulink kullanılmıştır. Her bir alt sistem için ayrı matematiksel modelleme fiziksel prensiplere dayandırılarak geliştirilmiştir. Alt sistemler arasındaki tutarlılığı sağlamak amaçlı eş-zamanlı mühendislik süreci boyunca farklı disiplinlerden uzmanlar tasarım kapladığı yerden yani tasarım zarfından başla- 
yarak eşleşen modellerin ara yüzleri, enerji sarfiyatları, performansları gibi konuları da gözeterek parametrik bir şekilde modellemiştir. Alt sistemlerin kavramsal tasarımı tamamlandıktan sonra giriş, lüle ve eşanjörlerin modelleri tasarıma uygun olacak şekilde güncellenmiştir. Her güncelleme sonrasında, doğru çalışmayı sağlamak amaçlı doğrulama analizleri yapılmıştır. Ön geliştirme süreci sonrası, alt sistemler daha ileri analizler ve simülasyon için çift yönlü entegre edilmiştir.

Tasarımın isterleri doğrultusunda ilk önce dış tedarik yolu ile kullanılacak olan kompresör ve gaz türbini seti seçilmiştir. Bu sayede imalat gereksinimleri sağlanıp, performans isterleri de karşılanmıştır. Sonra tüm fiziksel sistemlerin matematiksel modelleri hazırlanarak Simulink modeli içerisinde entegre edilmiş ve parametrik mikro-türbin modeli oluşturulabilmiştir. Çalışmalarda kullanılan matematiksel modeller aşağıda özetlenmektedir.

\subsection{Kompresor}

Tasarımda başlangıç olarak ön tasarım parametreleri ve ilgili varsayımsal değerler, seçilen kompresörün haritasından tasarım hedeflerini gerçekleştirmek ve beklenen güç tüketimini sağlamak amacıyla uygun değerler alınarak seçilmiştir. Bu tasarım için seçilen varsayımsal değerler operasyon hızı, kütle debisi ve sıkıştırma oranını kapsamaktadır. Kompresör haritası, çalıştırma ve durdurma koşulları haricinde kompresörün seçilmiş çalışma eğrisine karşılık ne kadar güç ürettiğini belirli bir güç yüzdesinde gösterir. Santrifüj tipi kompresör olarak Honeywell-Garrett firmasının GTX4294R tipi kompresörü seçilmiştir. Üretici tarafından sağlanan kompresör haritası digitalleştirildikten sonra, verimlilik değerleri basınç oranı ve kütle debisine göre grafikleştirilmiş-

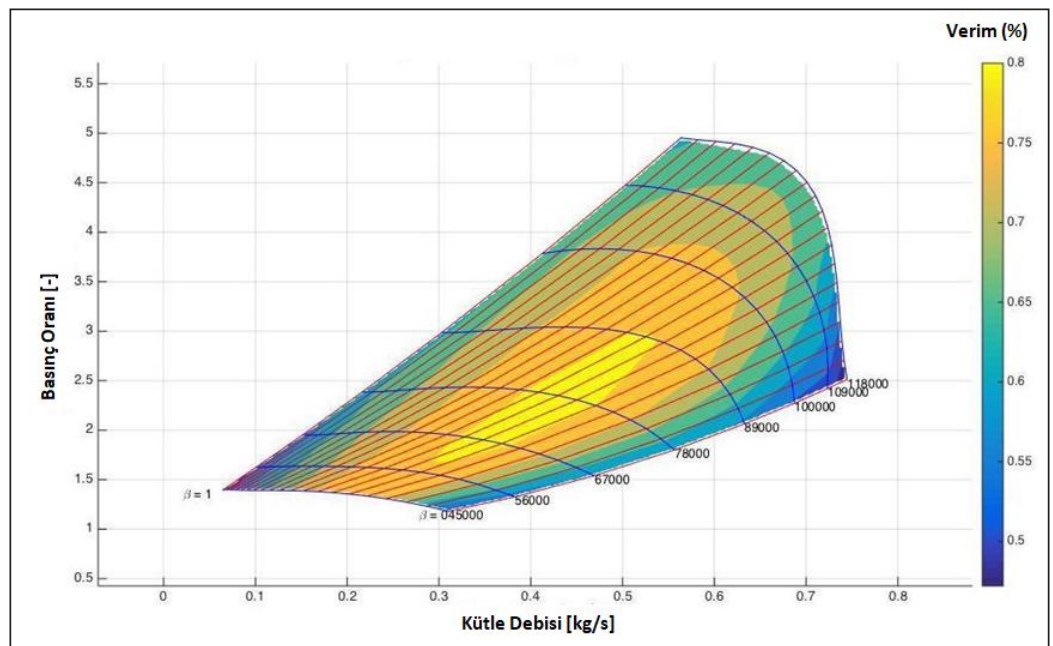

Şekil 3. Dijitalleştirilmiş Kompresör Haritası 
tir. En verimli çalışma noktasının seçilmesi ve tasarımla uyumu sağlandıktan sonra tasarım sürecinde bir sonraki noktaya geçilmiştir. Aşağıdaki grafikte, dijitalleştirilmiş kompesör haritası Şekil 3 'te gösterilmektedir.

Modelin güvenirliliği açısından, dinamik simülasyoun başlangıç değeri NewtonRaphson iterasyonuyla durağan hal çözümüne yakınsatılmıştır. Kompresör modeli doğrulanması için ise kompresör haritasında mümkün olduğunca çok noktayı kontrol ederek ve programı çalıştırarak analiz edilmiştir. Bu şekilde yapılan analizle model \%1 tork hataları hariç, kompresör davranışını çalışma aralığında güvenilir bir şekilde simüle edebilmektedir. Aynı zamanda, simülasyon modeli için MATLAB fonksiyon sayısı azaltılmış ve yazılan kodları $\mathrm{C} / \mathrm{C}++$ dillerine çevirerek Simulink’te çalışma süresini daha verimli hale getirilmiştir. Performans haritasındaki tüm çalışma koşullarının onaylanmasından sonra, dizayn metodolojisi gereği, kompresör modeli yanma odası modelinin geliştirilmesinde yardımcı olmak üzere sonlandırılmıştır.

\subsection{Yanma Odası}

Yanma odası tasarımı genellikle geliştirme ve modifikasyon sırasında oldukça fazla sayıda deneysel test gerektiren çok karmaşık, pahalı ve zaman alıcı bir süreçtir [3940]. Yanma odası modelini geliştirmek için 1-Boyutlu “A ̆ğ Modeli” esas alınmıştır. Buna neden olarak ise daha detaylı ve güvenilir yanma ve çıkış alev sıcaklığı verileri sağlaması gösterilir.

Öncelikle, yanma odası geometrisi ana bölgelere ayrılmıştır; birincil bölge, ikincil bölge ve seyreltme bölgesi ve de ayrıca sirkülasyon bölgesi olarak adlandırılan bir alt bölge bulunur (bkz. Şekil 4). Bu bölgelerin etrafını, alevin gelen havadan korunmasını sağlayan bir karter ve istikrarlı yanmanın gerçekleşmesi için uygun hava ilavesi görevini uygulayan gerekli alanlar oluşturur. Şekil 4'te, ana bölgeler ve yardımcı bölgeler başlıca olmak üzere yanma odasının genel bir gösterimi yapılmıştır.

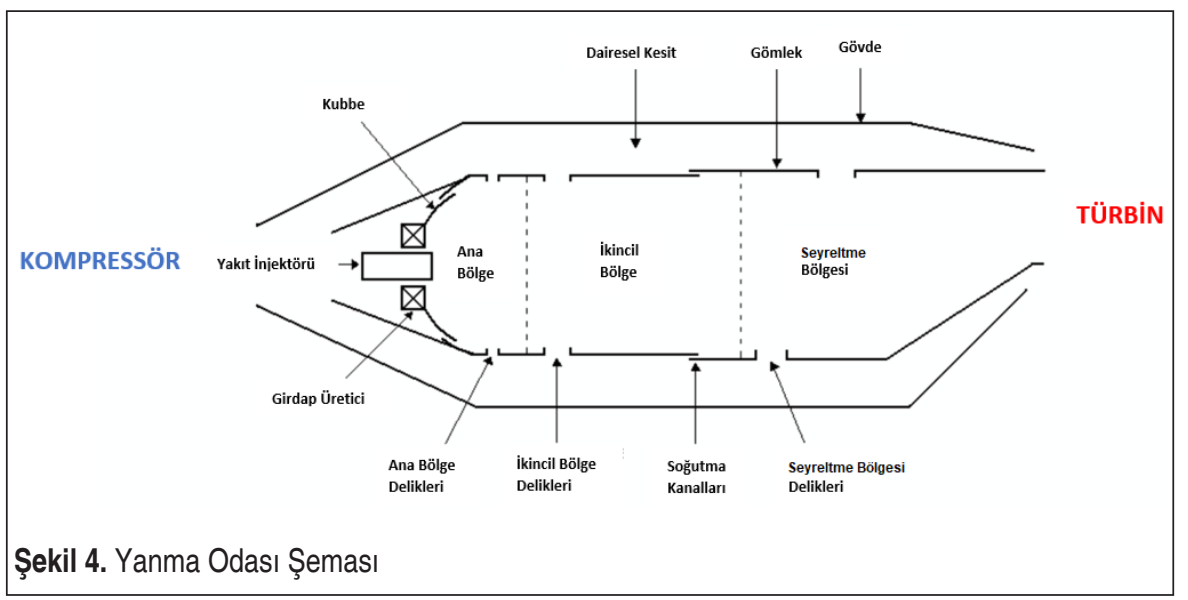


Parametrik modelleme sayesinde farklı yakıt türleri seçilebilir. Literatürde karşılaştırmalı modelleri olması sebebi ile ilk etapta Jet-A yakıtı seçilmiştir. Isı geçişi ve akışkanlar mekaniği temelleri uygulanarak geliştirilen model "girdap vanesi” tasarımı ile birleştirilmiş olup, yanma odası iteratif bir metotla türbinlere gereken gücü ve 1sıl değerleri gerçekleştirebilecek bir model tasarlanmıştır. Geliştirilen modelde, yanma geometrisi, bölge uzunluğu ve hava bölümleri, kubbe geometrisi için kanat sayısı ve kanat açısı gibi yanma odası tasarım parametrelerini gözeten çok sayıda analiz yapılmıştır. Kütle, momentum ve enerji korunumu yasaları kullanılarak oluşturulan ağ modeli, yanma odasının davranışını, çeşitli hava giriş koşullarına ve gelen kütle akıŞına karşılık gelen yakıt miktarına göre analiz edebilmektedir. Yanma odası modeli Simulink'e aktarıldıktan sonra, türbin tasarımı ve modellemesine geçilmiştir. Burada üretilen güç ise, aynı şafta bağlı olan alternatör ve diğer alt-sistemleri çalıştırmak için kullanılır.

\subsection{Türbin}

Türbin, kompresörün çalışmasına olanak sağlamak için gerekli yüksek basınç ve sıcaklıkta olan ve yanma odasında üretilen gazların genleşmesi yoluyla kompresörle bağlantılı şaftı döndürülmesi ile sorumludur. Tasarımda başlangıç olarak, kompresör ve yanma odası modellerinden elde edilen verilerle eşleşme sağlaması için gerekli

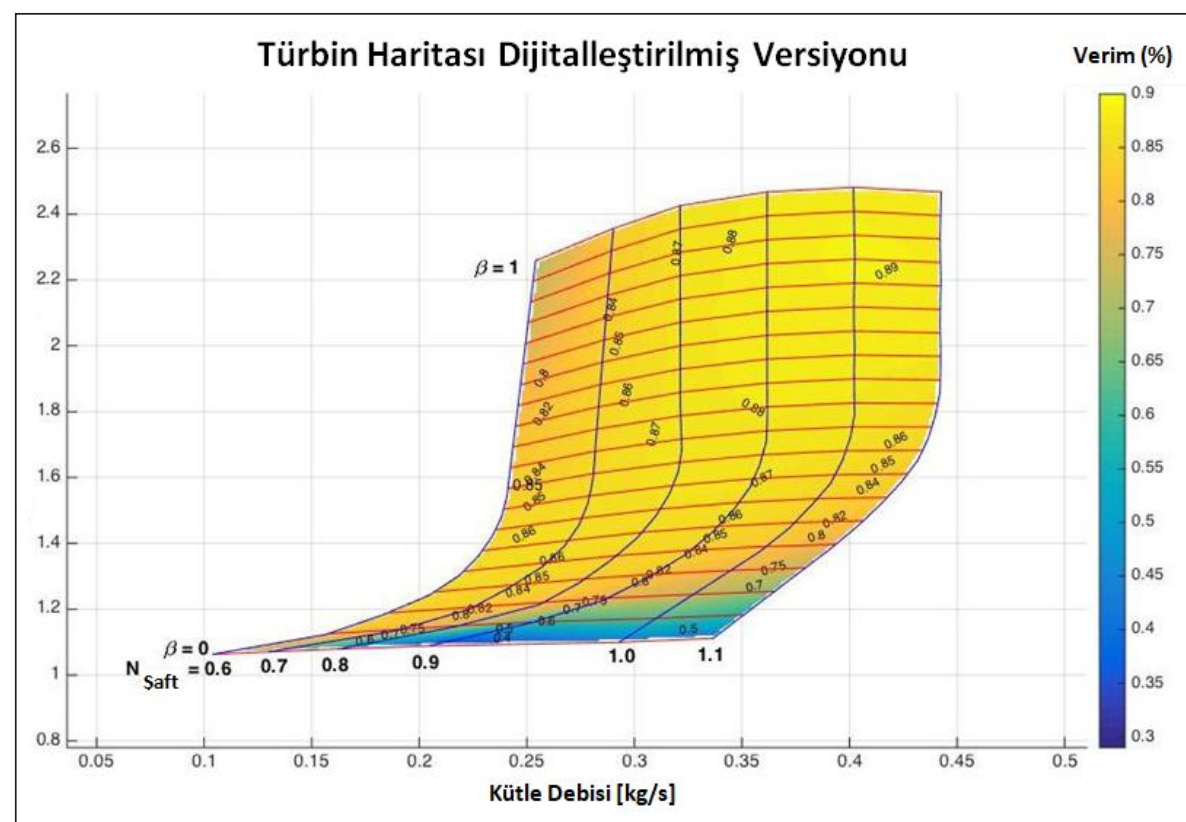

Şekil 5. Dijitalleştirilmiş Türbin Haritası 
ön tasarım parametreleri seçilmiştir. Sonra, sistemin tasarım hedeflerini karşılaması gereken tork ve gücü üretmek için bir endüstriyel performans haritası seçilmiştir.

Türbin haritası çalışma bakımından kompresör haritasıyla tamamen aynı olmakla birlikte, üretici tarafından sağlanan bir örnek olmaması dolayısıyla sistem ihtiyacına göre ölçeklendirilebilen bir türbin haritası oluşturulmuştur (bkz. Şekil 5). Sonrasında dijitalleştirilen bu harita, kompresör haritasında olduğu şekilde modele entegre edilmiştir. Sonuç olarak, tasarım noktası için basınç oranı ve kütle debisi değerleri, kompresör ve yanma odası arasındaki eşleşmeye yönelik mikro türbin sistemi tasarım değerlerine göre ölçeklendirilmiştir.

Türbin modelinin doğrulanması için türbin haritasındaki çok sayıda noktanın analiz edilmesi gerekmektedir. Tork hata noktalarıyla beraber analiz edilen harita, \% 0,2 tork hataları hariç oldukça güvenilir ve güçlü bir doğrulukla sonuç vermektedir. $\mathrm{Bu}$ onaylama, türbin performansının simülasyon için güvenilir olduğunu gösterir. Son olarak ise, türbin modeli Simulink'e aktarılmıştır ve kompresör ve yanma odasının modellerine paralel olarak hızlı bir şekilde çözüme ulaşabilmektedir.

\subsection{Eşanjör ve Reküperatör}

Enerjinin korunumu presibi ve 1S1 geçişi bağıntıları kullanılarak oluşturulan eşanjörler, egzoz gazının yüksek sıcaklıklarda sistemi terk etmesini önlemenin yanı sıra, sistemde kullanılan suyun 1sısını yükselterek, sistemin sıcak su çıkışına sahip olmasını sağlamıştır. Reküperatör ise, atık ısıyı kazanmak üzere, sıkıştırılmış havanın yanma odasına girişinden önce ısıtılması ve böylelikle daha yüksek verimlerde çalışarak kullanılacak yakıtın azaltılmasını amaçlanmıştır. Temel olarak sıcak gazdan basınçlı havaya ısı geçişi sağlar ve bunun arttırılması yüzey alanını ile doğru orantılıdır. Hem eşanjör hem de reküperatörün basit 1sı geçişi bağıntılarıyla modellenmesi kolaylık sağlamakla beraber, sisteme uyumu da büyük ölçüde sağlamıştır. Diğer alt sistemler gibi, eşanjör ve reküperatör de Simulink ortamında modellenmiştir.

\subsection{Alternatör}

Alternatör, mekanik enerjiden, mikro-türbin tasarımında doğrudan şafttan, elektrik enerjisi üretmek amacıyla kullanılmıştır. Bunun gerçekleştirmek için, kompresörün devriyle alternatörün çalışma aralığı belirli bir zarf içerisinde kalmalıdır. Bundan ötürü türbin şaftına planet dişli sistemi ile bağlanmıştır. Bu alt sistemi modellemek için ve aynı zamanda bütün sistemin güvenilirliğini tümüyle gerçekçi kılmak amacıyla endüstriyel bir alternatör kullanılmıştır. Seçilen alternatör ise $5 \mathrm{~kW}$ anma gücünde ticari bir alternatördür. Planet dişlisinin kullanılmasının yanı sıra, alternatörün devir sayısını kompresörle eşlenmesinde aynı zamanda tork dengesi de ele alınmıştır. Bu nedenle, türbin, kompresör ve alternatör arasındaki torkları dengelemek için mikro- 
türbin ancak \% 60 veya daha yüksek devirlerde çalışırken alternatörü şafta angaje etmek üzere programlanmıştır.

\subsection{Modellerin Birleştirilmesi ve Genel Sistemin Karşılaştırılması}

Tüm alt bileşenler modellenip (bkz. Şekil 6), dinamik davranışları analiz edilmek üzere Simulink'e aktarılmıştır. Daha sonra tüm alt sistemler birbirleriyle karşılaştırılmış ve bileşenler arasındaki tutarlılığı sağlamak için eşzamanlı mühendislik metodu kullanılmıştır: Farklı disiplinler açısından tüm alt sistemlerin birbiri ile uyumlu çalışması, tasarım zarfina uyum ve performans çıktıları incelenmiştir.

Şekil 6'da yer alan sistemde kompresör aracılığıyla sisteme giren hava reküperatörden geçerek isıtılarak yanma odasına sokulmaktadır. Sonrasında türbin ile genleştirilen sıcak hava kompresörden gelen soğuk havayı 1sıtmak için reküperatörden geçerek akabinde başka bir 1sı dönüştürücüsüne girmektedir. Burada da bir tanka bağlı dolaşımda olan suyu ısıtmak için son kez kullanılarak devreden çıkarılır. Aynı zamanda türbin hem alternatör hem de kompresör sistemine bağlı olan şaftı çevirerek enerji üretimini sağlamaktadır. Kompresörün ve türbin aynı şaft üzerinde yer aldığı için çalışma noktası tork dengelemesi metodu ile bir kök bulma problemi şeklinde ifade edilerek Newton-Raphson algoritması ile hesaplanmıştır. Haritalar (kompresör ve türbin) gücün ve dolayısı ile tork hesabında kullanılmaktadır. Bu sayede hava/yakıt oranı için doğrudan numerik girdi yapılmasına gerek olmadan girilen yakıt debisine cevap olarak sistemin devrini kendisinin tayin etmesi sağlanmıştır.

Bunun için öncelikle sistemin güvenirliliğini ve gerçekçiliğini test etmek amaçlı, endüstride kullanılmış ve verilerinden yararlanılabilen bir doğrulama gerekmektedir. Bu amaçla J-85 motoruna ait kompresör haritası kullanılmış olup, sonuçlar geliştirilmiş modelin her tür gaz türbini için kullanılabileceğini ve gerçekçi sonuçlar verdiğini doğrulamıştır. Modelin doğrulanması, artık mikro-türbin tasarımının gerçek-zamanlı bir simülayon aracı olarak kullanılabilmesini ve farklı varyasyonlarda gerçekçi sonuçlar alınabilmesini sağlamıştır. Böylece parametrik deneme yanılmalar, alt sistemlerin farklı seçilmesi ya da farklı noktalarda çalıştırılması sonucu performans etkileşimlerinin incelenmesi mümkün kılınmıştır.

Mikro-türbin sisteminin limitleri belirlenerek basit bir kontrol algoritması eklenmesi ile model güncellenerek tam otonom dijital bir motor kontrolcüsüne (FADEC) yönelik çalışmaları da yapılabilecek bir ortam sunulmuştur. Kısa vadede FADEC'i temsil edebilmek için gösterge ve kontrol sisteminin kombinasyonu ile mikro-türbinin güçlü bir görsel sunumu sağlamıştır. Bu göstergeler sayesinde, kompresör ve türbin sıkıştırma/genleşme oranları, kütle debisi, çıkış sıcaklıkları, devir ve mikro-türbin iç sıcaklığının gösterimi sağlanmış olup tam otonom bir sistem geliştirilmiştir. Böylece daha ucuz ve daha kolay üretilebilen, otomotiv, havacılık ve diğer endüstrilerde kullanılması amaçlanan oldukça gerçekçi bir mikro-türbin modeli geliştirilmiştir. 


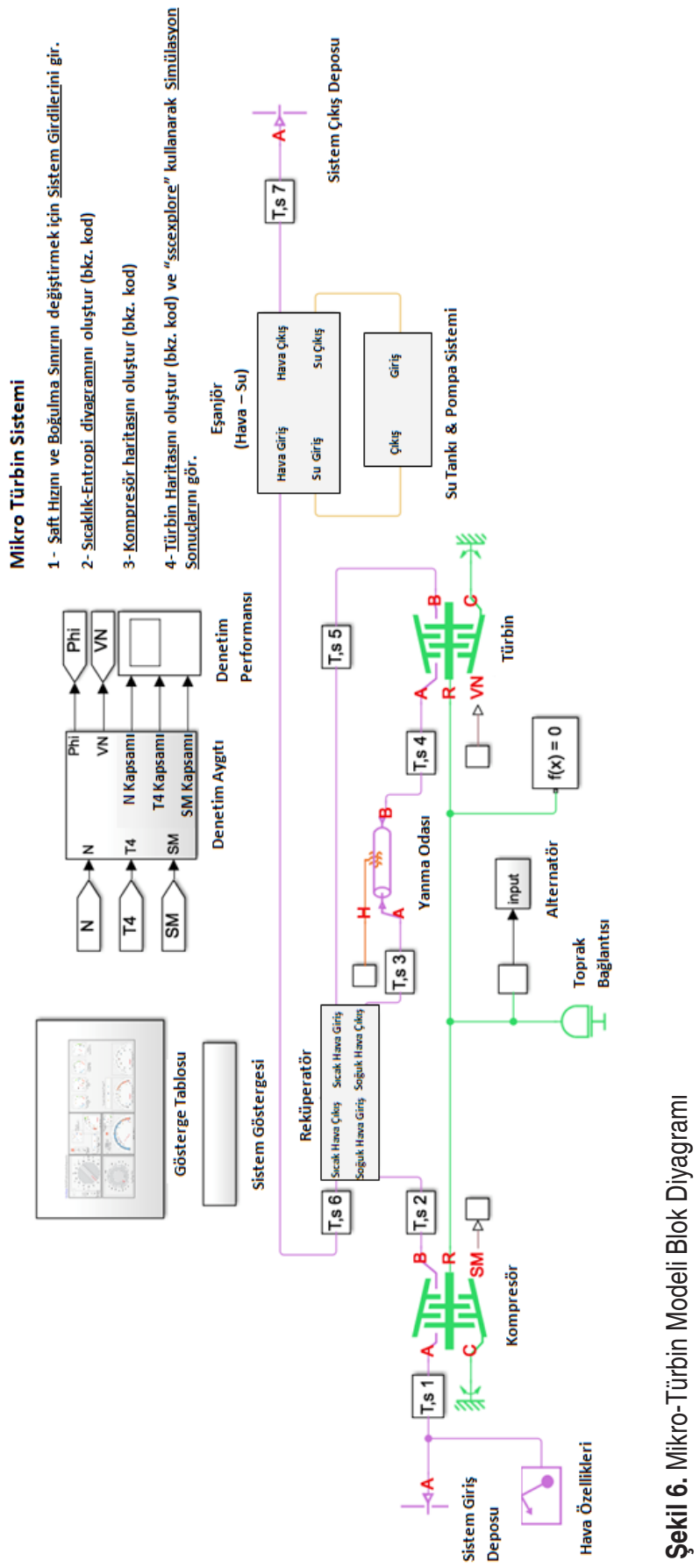




\section{SONUÇ}

Model tabanlı tasarım ile eş-zamanlı mühendislik, çok disiplinli dalların etkileşimini ve çalışma süreçlerini etkili bir derecede kolaylaştıran bir yöntem olarak kullanılabilir. Özellikle yazılım ortamında geliştirilen matematiksel alt sistem modelleri, tüm işletim zarfinda sistem dinamiklerini incelemek için kullanılabilmekte, ek olarak da en iyi tasarım noktasını bulmakta faydalı olmaktadır. Aynı zamanda eş-zamanlı tasarım süreci sistemin belirsiz ön aşamalarının sürekli devam eden bilgi paylaşımı ve etkileşimi sayesinde hızlı bir şekilde çözümlenmesinde yararlı olmaktadır. Bu sayede çoklu-disiplinli ekipler, sistemin farklı parçalarını aynı anda çalıştırabilmekte, dolayısıyla proje yönetimine hız ve bütçe korunumu sağlamaktadır. Tüm bunlara V-döngüsü sistem mühendisliği tasarım parametrelerinin süreç boyunda ayarlanmasını sağlayarak dâhil edildiğinde, gaz türbini gibi karmaşık sistemlerin tasarımı etkili bir şekilde yürütülebilmekte ve teknik isterlere uygun bir şekilde sonuçlandırılabilmektedir.

\section{TEŞEKKÜR}

Bu çalışma sırasında sağladığı desteklerden dolayı Melina Aero Teknoloji Geliştirme ve Dizayn Bürosu A.Ş.'ne teşekkür ederiz. Finansal destek TÜBİTAK-TEYDEB tarafindan 2150113 numaralı proje çerçevesinde sağlanmıştır. Proje için kuluçka ofisinde yer tahsis eden İTÜ-Arı Teknokent'e ayrıca şükranlarımızı sunarız.

\section{KAYNAKÇA}

1. Paterno, P. 1999. "Model-Based Design and Evaluation of Interactive Applications", Springer-Verlag, Londra, s. 11.

2. Wang, S. and Shin, K. G. 2006. "Task Construction for Model-Based Design of Embedded Control Software”, IEEE Trans. Software Eng, Cilt 32, Sayı 4, sf. 254-265.

3. Horner, N. C. and Topper, J. S. 2013. "Model-Based Systems Engineering in Support of Complex Systems Development”, Johns Hopkins APL Technical Digest, Cilt 32, Say1 1, sf. 419-432.

4. Plötzner, R., Hoppe, H. U., Fehse, E., Nolte, C. and Tewissen, F. 2001. "Model-based Design of Activity Spaces for Collaborative Problem Solving and Learning", Proceedings of the European Conference on Artificial Intelligence in Education, Lizbon, Portekiz, sf. $372-378$.

5. Heemels, W. P. M. H. and Muller, G. 2006. "Boderc: Model-based design of high-tech systems", Eindhoven Embedded Systems Institute, Hollanda.

6. Yang, N., Hua, G. and Li-li, J. 2016. "Model-Based Design Methodology for Sampling Rate Converter", International Journal of Multimedia and Ubiquitous Engineering, Cilt 11, Say1 5, sf. 83-92.

7. Santos, M. M. D., Neme, J. H., Franco, F. R., Stevan, S. L., Torres, W., Lugli, A. B., 
Lagana, A. A. M. and Justo, J. F. 2015. "Model-Based Design of Exterior Lighting Control Function for Automobile - MIL", SIL and RCP, International Journal of Innovative Computing, Information and Control, Cilt 11, Say1 5, sf. 1495-1507.

8. Kirby, B., Zou, L., Cao, J., Kamwa, I., Heniche, A. and Dobrescu, M. 2011. "Development of a Predictive Out of Step Relay Using Model Based Design", Innovative Smart Grid Technologies - ISGT Europe Conference, IEEE, sf. 1-6.

9. Chatterjee, S. and Kleijn, W. B. 2011. "Auditory Model-Based Design And Optimization Of Feature Vectors for Automatic Speech Recognition”, IEEE Transactions on Audio, Speech, and Language Processing, Cilt. 19, Sayı. 6, sf. 1813-1825.

10. Miyajima, T., Fujimoto, H. and Fujitsuna, M. 2013. "A Precise Model-Based Design Of Voltage Phase Controller for IPMSM”, IEEE Transactions on Power Electronics, Cilt. 28, Say1. 12, sf. 5655-5664.

11. Ahmadian, M., Nazari,Z.J.,Nakhaee,N.andKostic,Z. 2005. "Model-Based Design and SDR", 2nd IEEE/EURASIP Conference, sf. 19-99.

12. Solano, S. S., Jimenez, M. B., Toro, E. D., Jimenez, P. B. and Baturone, I. 2013. "Model-Based Design Methodology for Rapid Development of Fuzzy Controllers on FPGAs", IEEE Transactions on Industrial Informatics, Cilt 9, Say1 3, sf. 1361-1370.

13. Fu, Y. and Gu, X. 1997. "Discrete Maths And Its Application", Publishing House of Electrical Industry, Beijing, China.

14. Quan, W. and Jianmin, H. 2006. "A Study on Collaborative Mechanism for Product Design in Distributed Concurrent Engineering", Proceedings of the 7th International Conference on Computer-Aided Industrial Design and Conceptual Design - CAIDCD, sf. $1-5$.

15. Abdalla, H. S. 1999. "Concurrent Engineering for Global Manufacturing”, International Journal of Production Economics, Cilt. 60-61, sf. 251-260.

16. Ma, Y., Chen, G. and Thimm, G. 2008. "Paradigm Shift: Unified and Associative Feature-based Concurrent Engineering and Collaborative Engineering", Journal of Intelligent Manufacturing, Cilt 19, Say1 6, sf. 625-641.

17. Krishman, V. 1996. "Managing The Simultaneous Execution of Coupled Phases in Concurrent Product Development”, IEEE Transaction on Management, Cilt 43, Sayı 2, sf. $210-217$.

18. Assine, A., Falkenburg, D., and Chelst, K. 1999. "Engineering Design Management: An Information Structure Approach", International Journal of Product Research, Cilt 37, Sayı 13, sf. 2957-2975.

19. Tang, D., Cheng, L., Li, Z., Li, D. and Zhang, S. 2000. "Re-Engineering of The Design Process for Concurrent Engineering", Computers and Industrial Engineering, Cilt 38, Say1 4, sf. 479-491.

20. Kusiak, A. 1993. "Concurrent Engineering: Automation, Tools and Techniques", John Wiley and Sons. 
21. Rosenblatt, A. And Watson, G. 1991. "Concurrent Engineering”, IEEE Spectrum, sf. $22-37$.

22. Mani, M., Manikandan, K. and Manikandan, M. 2015. "Design for Manufacturing Based On Concurrent Engineering", International Journal of Innovative Research in Science, Engineering and Technology, Cilt 4, Say1 2, sf. 128-131.

23. Wolf, W. 2001. "Computers as Components: Principles of Embedded Computing System”, Elsevier, Burlington, MA.

24. Sullivan, W. G. and Parsaei, H. R. 1993. "Concurrent Engineering: Contemporary Issues and Modern Design Tools", Chapman and Hall.

25. Bahler, D., Bowen, J., O'Grady, P. and Young, R. E. 1990. "Issues in Design/ Manufacturing Integration", Winter Annual Meeting of the ASME, Dallas, TX, November 25-30, sf. 59-67.

26. Sobek, D. K., Ward, A. C. and Liker, J. K. 1999. "Toyota's Principles of Set-Based Concurrent Engineering”, MITSloan Management Review, Cilt 40, Say1 2, sf. 67-83.

27. Taylor A. 1997. "How Toyota Defies Gravity", Fortune, Cilt 136, sf. 100-108.

28. Ivanov, A., Noca, M., Borgeaud, M., Felloni, F., Guzman, E., Fueglistaler, A., Gallay, S. and Triguero-Baqtista, A. 2010. "Concurrent Design Facility at the Space Center EPFL", SECESA.

29. ESA, 2011. "The ESA Concurrent Design Facility: Concurrent Engineering Applied to Space Mission Assessments", http://esamultimedia.esa.int/docs/cdf/CDFINFOPACK-2011.pdf, son erişim tarihi: 24.04.2017.

30. V-Modell@XT, 1997. "Limits of the V Model”, http://v-modell.iabg.de/XThtmleng/ index.html, son erişim tarihi: 24.04.2017.

31. Forsberg, K. and Mooz, H. 1991. "The Relationship of System Engineering to the Project Cycle", Proceedings of the First Annual Symposium of National Council on System Engineering, sf. 57-65.

32. Forsberg, K., Mooz, H. and Cotterman, H. 2005. "Visualizing Project Management", 3. bask1, John Wiley and Sons, New York, Amerika Birleşik Devletleri.

33. DeSpautz, J., Kovacs, K. S. and Werling, G. 2008. "GAMP Standards For Validation of Automated Systems", Pharmaceutical Processing.

34. Federal Highway Administration (FHWA), 2005. "Clarus Concept of Operations", Publication Say1 FHWA-JPO-05-072.

35. Narang, R. 2015. "Software Engineering - Principles and Practices", Mc-Graw - Hill, New York, Amerika Birleşik Devletleri.

36. Sobkiw, W. 2008. "Sustainable Development Possible with Creative System Engineering”, Cassbeth.

37. Defense AT\&L, 2006. "A New Systems Engineering Model and an Old", Familiar 
Friend; Figure 2 V-9 Process Interactions, p. 51, son erişim tarihi: 24.04.2017.

38. International Council On Systems Engineering (INCOSE), 2007. "Systems Engineering Handbook Version 3.1", sf. 3.3 - 3.8.

39. Lawson, R. J. May 1993, "Computational Modeling of an Aircraft Engine Combustor to Achieve Target Exit Temperature Profiles", ASME 1993 International Gas Turbine and Aeroengine Congress and Exposition.

40. Eccles, N. C. and Priddin, C. H., Accelerated, Sep 1999. "Combustion Design using CFD”, 14th International Symposium on Air Breathing Engines. 